\title{
CFD modeling of flow pattern in spillway's approach channel
}

\author{
Abbas Parsaie $^{1}$ - Amir Hamzeh Haghiabi ${ }^{1}$ - Amir Moradinejad ${ }^{1}$
}

Received: 28 April 2015/Accepted: 28 August 2015/Published online: 15 September 2015

(C) Springer International Publishing 2015

\begin{abstract}
Analysis of behavior and hydraulic characteristics of flow over the dam spillway is a complicated task that takes lots of money and time in water engineering projects planning. To model those hydraulic characteristics, several methods such as physical and numerical methods can be used. Nowadays, by utilizing new methods in computational fluid dynamics (CFD) and by the development of fast computers, the numerical methods have become accessible for use in the analysis of such sophisticated flows. The CFD softwares have the capability to analyze two- and three-dimensional flow fields. In this paper, the flow pattern at the guide wall of the Kamal-Saleh dam was modeled by Flow 3D. The results show that the current geometry of the left wall causes instability in the flow pattern and making secondary and vortex flow at beginning approach channel. This shape of guide wall reduced the performance of weir to remove the peak flood discharge.
\end{abstract}

Keywords Approach channel · Kamal-Saleh dam · Guide wall Flow pattern $\cdot$ Numerical modeling . Flow 3D software

Abbas Parsaie

abbas_parsaie@yahoo.com

Amir Hamzeh Haghiabi

Haghiabi@yahoo.com

Amir Moradinejad

amir_24619@yahoo.com

1 Department of Water Engineering, Lorestan University, Khorram Abad, Iran

\section{Introduction}

Spillways are one of the main structures used in the dam projects. Design of the spillway in all types of dams, specifically earthen dams is important because the inability of the spillway to remove probable maximum flood (PMF) discharge may cause overflow of water which ultimately leads to destruction of the dam (Das and Saikia et al. 2009; E 2013 and Novak et al. 2007). So study on the hydraulic characteristics of this structure is important. Hydraulic properties of spillway including flow pattern at the entrance of the guide walls and along the chute. Moreover, estimating the values of velocity and pressure parameters of flow along the chute is very important (Chanson 2004; Chatila and Tabbara 2004). The purpose of the study on the flow pattern is the effect of wall geometry on the creation transverse waves, flow instability, rotating and reciprocating flow through the inlet of spillway and its chute (Parsaie and Haghiabi 2015a, b; Parsaie et al. 2015; Wang and Jiang 2010). The purpose of study on the values of velocity and pressure is to calculate the potential of the structure to occurrence of phenomena such as cavitation (Fattor and Bacchiega 2009; Ma et al. 2010). Sometimes, it can be seen that the spillway design parameters of pressure and velocity are very suitable, but geometry is considered not suitable for conducting walls causing unstable flow pattern over the spillway, rotating flows at the beginning of the spillway and its design reduced the flood discharge capacity (Fattor and Bacchiega 2009). Study on spillway is usually conducted using physical models (Su et al. 2009; Suprapto 2013; Wang and Chen 2009; Wang and Jiang 2010). But recently, with advances in the field of computational fluid dynamics (CFD), study on hydraulic characterist-ics of this structure has been done with these techniques (Chatila and Tabbara 2004; Zhenwei et al. 
2012). Using the CFD as a powerful technique for modeling the hydraulic structures can reduce the time and cost of experiments (Tabbara et al. 2005). In CFD field, the Navier-Stokes equation is solved by powerful numerical methods such as finite element method and finite volumes (Kim and Park 2005; Zhenwei et al. 2012). In order to obtain closed-form Navier-Stokes equations turbulence models, such $k-\varepsilon$ and Re-Normalisation Group (RNG) models have been presented. To use the technique of computational fluid dynamics, software packages such as Fluent and Flow 3D, etc., are provided. Recently, these two software packages have been widely used in hydraulic engineering because the performance and their accuracy are very suitable (Gessler 2005; Kim 2007; Kim et al. 2012; Milési and Causse 2014; Montagna et al. 2011). In this paper, to assess the flow pattern at Kamal-Saleh guide wall, numerical method has been used. All the stages of numerical modeling were conducted in the Flow 3D software.

\section{Materials and methods}

Firstly, a three-dimensional model was constructed according to two-dimensional map that was prepared for designing the spillway. Then a small model was prepared with scale of 1:80 and entered into the Flow 3D software; all stages of the model construction was conducted in AutoCAD 3D. Flow 3D software numerically solved the Navier-Stokes equation by finite volume method. Below is a brief reference on the equations that used in the software. Figure 1 shows the 3D sketch of Kamal-Saleh spillway and Fig. 2 shows the uploading file of the Kamal-Saleh spillway in Flow 3D software.

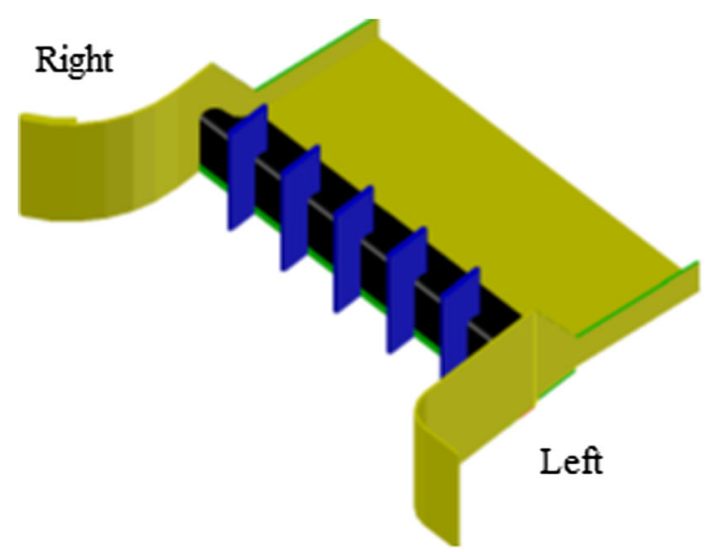

Fig. 1 Sketch of approach channel and spillway of the Kamal-Saleh dam

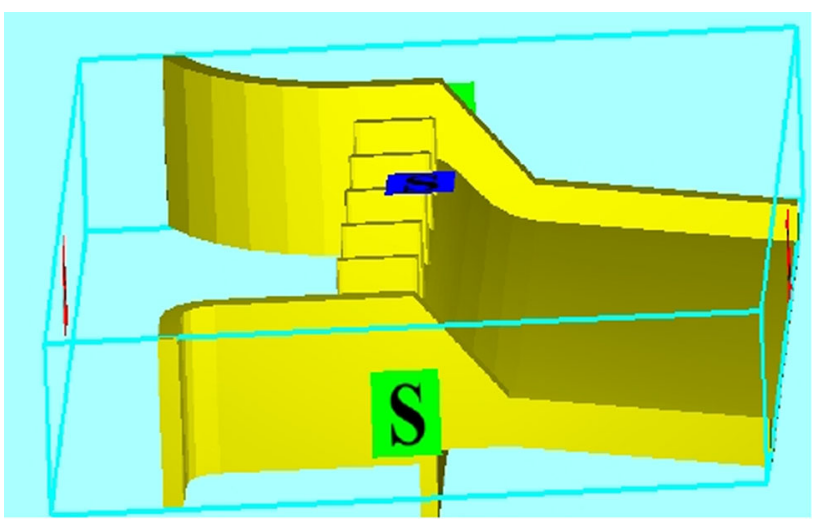

Fig. 2 The 3D model of Kamal-Saleh dam in Flow 3D software

\section{Review of the governing equations in software Flow 3D}

Continuity equation at three-dimensional Cartesian coordinates is given as $\mathrm{Eq}(1)$.

$v_{\mathrm{f}} \frac{\partial \rho}{\partial t}+\frac{\partial}{\partial x}\left(u A_{\mathrm{x}}\right)+\frac{\partial}{\partial x}\left(v A_{\mathrm{y}}\right)+\frac{\partial}{\partial x}\left(w A_{\mathrm{z}}\right)=\frac{\text { PSOR }}{\rho}$,

where $u, v, z$ are velocity component in the $\mathrm{x}, \mathrm{y}, \mathrm{z}$ direction; $A_{\mathrm{x}}, A_{\mathrm{y}}, A_{\mathrm{z}}$ cross-sectional area of the flow; $\rho$ fluid density; PSOR the source term; $v_{\mathrm{f}}$ is the volume fraction of the fluid and three-dimensional momentum equations given in Eq (2).

$$
\begin{aligned}
\frac{\partial u}{\partial t}+\frac{1}{v_{\mathrm{f}}}\left(u A_{\mathrm{x}} \frac{\partial u}{\partial x}+v A_{\mathrm{y}} \frac{\partial u}{\partial y}+w A_{\mathrm{z}} \frac{\partial u}{\partial z}\right) & =-\frac{1}{\rho} \frac{\partial P}{\partial x}+G_{\mathrm{x}}+f_{\mathrm{x}} \\
\frac{\partial v}{\partial t}+\frac{1}{v_{\mathrm{f}}}\left(u A_{\mathrm{x}} \frac{\partial v}{\partial x}+v A_{\mathrm{y}} \frac{\partial v}{\partial y}+w A_{\mathrm{z}} \frac{\partial v}{\partial z}\right) & =-\frac{1}{\rho} \frac{\partial P}{\partial y}+G_{\mathrm{y}}+f_{\mathrm{y}}, \\
\frac{\partial w}{\partial t}+\frac{1}{v_{\mathrm{f}}}\left(u A_{\mathrm{x}} \frac{\partial w}{\partial x}+v A_{\mathrm{y}} \frac{\partial w}{\partial y}+w A_{\mathrm{z}} \frac{\partial w}{\partial z}\right) & =-\frac{1}{\rho} \frac{\partial P}{\partial y}+G_{\mathrm{z}}+f_{\mathrm{z}}
\end{aligned}
$$

where $P$ is the fluid pressure; $G_{\mathrm{x}}, G_{\mathrm{y}}, G_{\mathrm{z}}$ the acceleration created by body fluids; $f_{\mathrm{x}}, f_{\mathrm{y}}, f_{\mathrm{z}}$ viscosity acceleration in three dimensions and $v_{\mathrm{f}}$ is related to the volume of fluid, defined by Eq. (3). For modeling of free surface profile the VOF technique based on the volume fraction of the computational cells has been used. Since the volume fraction F represents the amount of fluid in each cell, it takes value between 0 and 1 .

Table 1 Characteristics and dimensions of the guidance walls tested

\begin{tabular}{lllc}
\hline Case & Direct length $(\mathrm{m})$ & Radius of curvature $(\mathrm{m})$ & Curvature $\left(^{\circ}\right)$ \\
\hline 1 & 0.200 & 0.325 & 90 \\
2 & 0.375 & 0.175 & 120 \\
3 & 0.100 & 0.400 & 110 \\
\hline
\end{tabular}


Fig. 3 Flow pattern in the approach channel for the flow rate $80(\mathrm{~L} / \mathrm{s})$

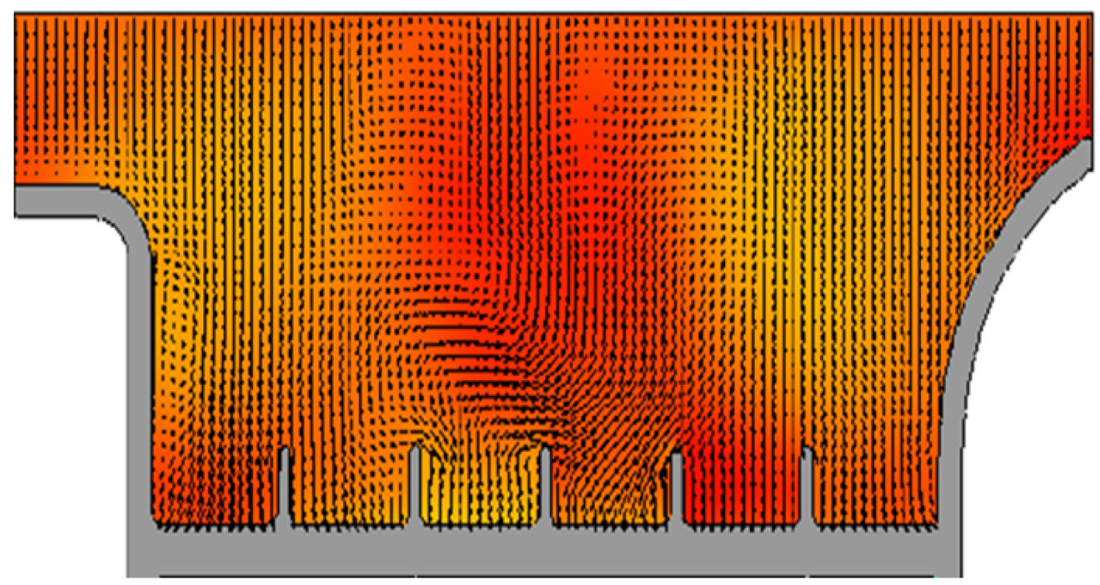

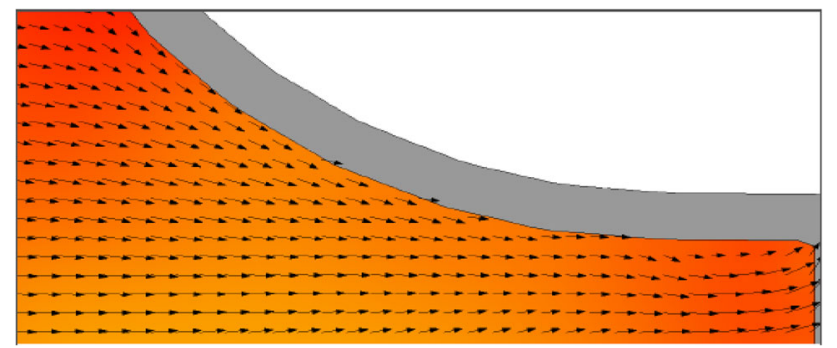

Fig. 4 Flow pattern trough the right side guide wall

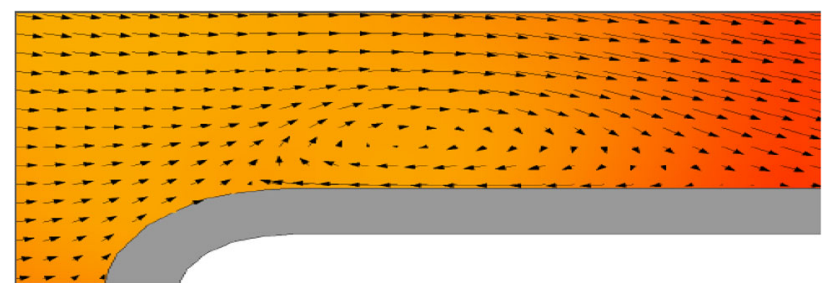

Fig. 5 Flow pattern trough the left side guide wall

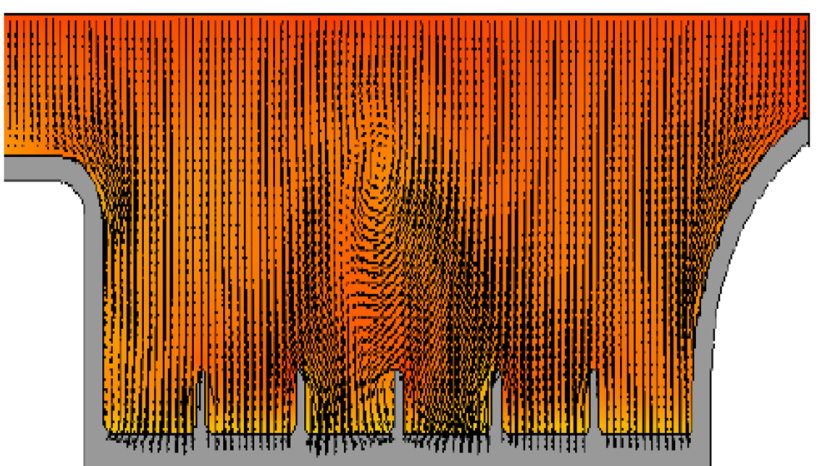

Fig. 6 Proposed model for the flow rate of $100(\mathrm{~L} / \mathrm{s})$

$$
\frac{\partial F}{\partial t}+\frac{1}{v_{\mathrm{f}}}\left[\frac{\partial}{\partial x}\left(F A_{\mathrm{x}} u\right)+\frac{\partial}{\partial y}\left(F A_{\mathrm{y}} v\right)+\frac{\partial}{\partial y}\left(F A_{\mathrm{z}} w\right)\right]=0
$$

\section{Turbulence models}

Flow 3D offers five types of turbulence models: Prantl mixing length, $k-\varepsilon$ equation, RNG models, Large eddy simulation model. Turbulence models that have been proposed recently are based on Reynolds-averaged NavierStokes equations. This approach involves statistical methods to extract an averaged equation related to the turbulence quantities.

\section{Steps of solving a problem in Flow 3D software}

(1) Preparing the 3D model of spillway by AutoCAD software. (2) Uploading the file of 3D model in Flow 3D software and defining the problem in the software and checking the final mesh. (3) Choosing the basic equations that should be solved. (4) Defining the characteristics of fluid. (5) Defining the boundary conditions; it is notable that this software has a wide range of boundary conditions. (6) Initializing the flow field. (7) Adjusting the output. (8) Adjusting the control parameters, choice of the calculation method and solution formula. (9) Start of calculation. Figure 1 shows the 3D model of the Kamal-Saleh spillway; in this figure, geometry of the left and right guide wall is shown.

Figure 2 shows the uploading of the 3D spillway dam in Flow 3D software. Moreover, in this figure the considered boundary condition in software is shown. At the entrance and end of spillway, the flow rate or fluid elevation and outflow was considered as BC. The bottom of spillway was considered as wall and left and right as symmetry. 
Fig. 7 Flow pattern down the right wall

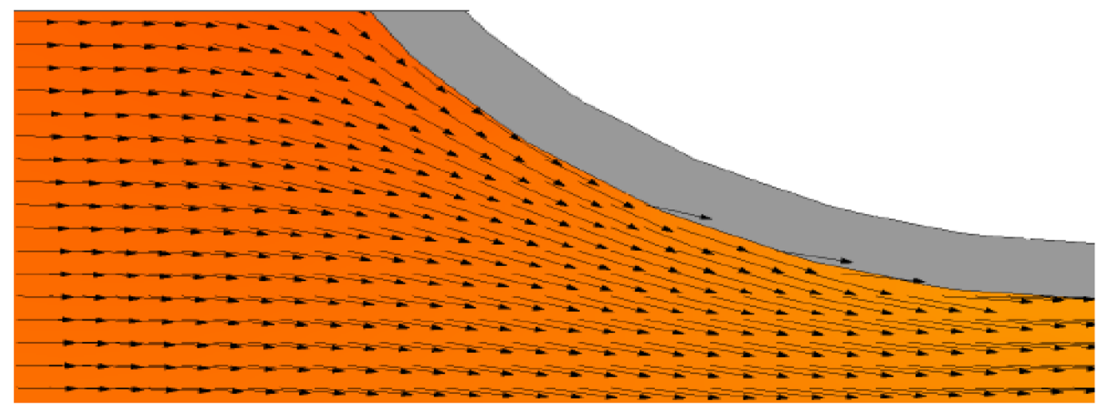

Fig. 8 Pattern of flow through the sidewall of the left
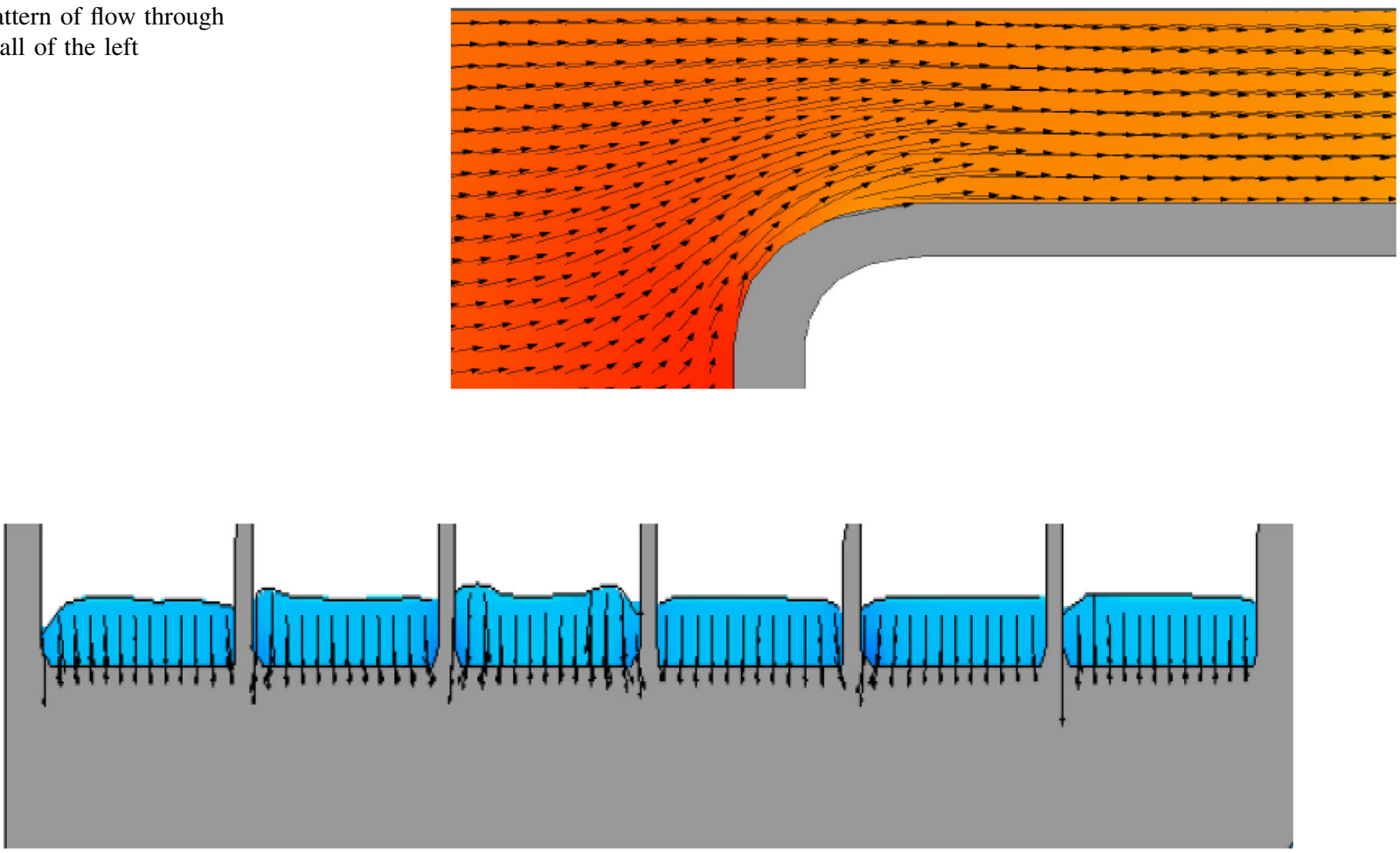

Fig. 9 Two-dimensional flow pattern on the spillway crest

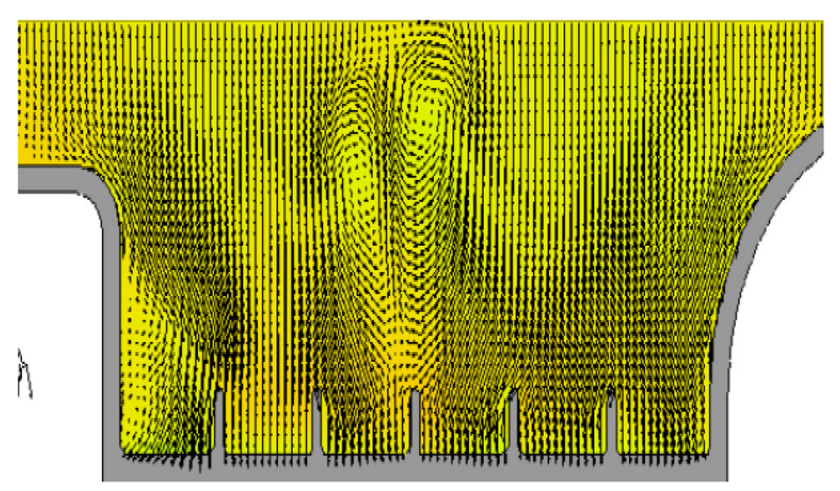

Fig. 10 Flow pattern in the design flow of $120(\mathrm{~L} / \mathrm{s})$

\section{Model calibration}

Calibration of the Flow 3D for modeling the effect of geometry of guide wall on the flow pattern is included for comparing the results of Flow 3D with measured water surface profile. Calibration the Flow 3D software could be conducted in two ways: first, changing the value of upstream boundary conditions is continued until the results of water surface profile of the Flow 3D along the spillway successfully covered the measurement water surface profile; second is the assessment the mesh sensitivity. Analyzing the size of mesh is a trial-and-error process where the size of mesh is evaluated form the largest to the 
Fig. 11 Flow pattern near the wall in right direction

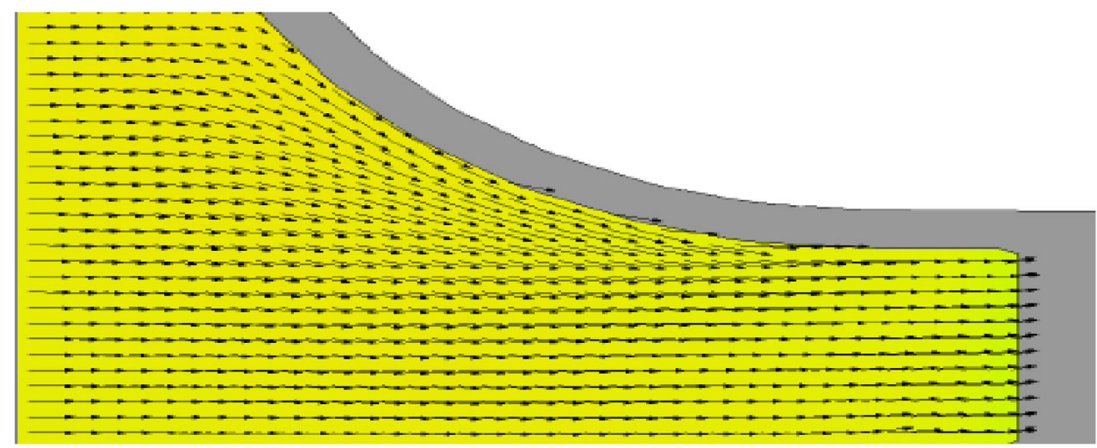

Fig. 12 Flow pattern near the left wall
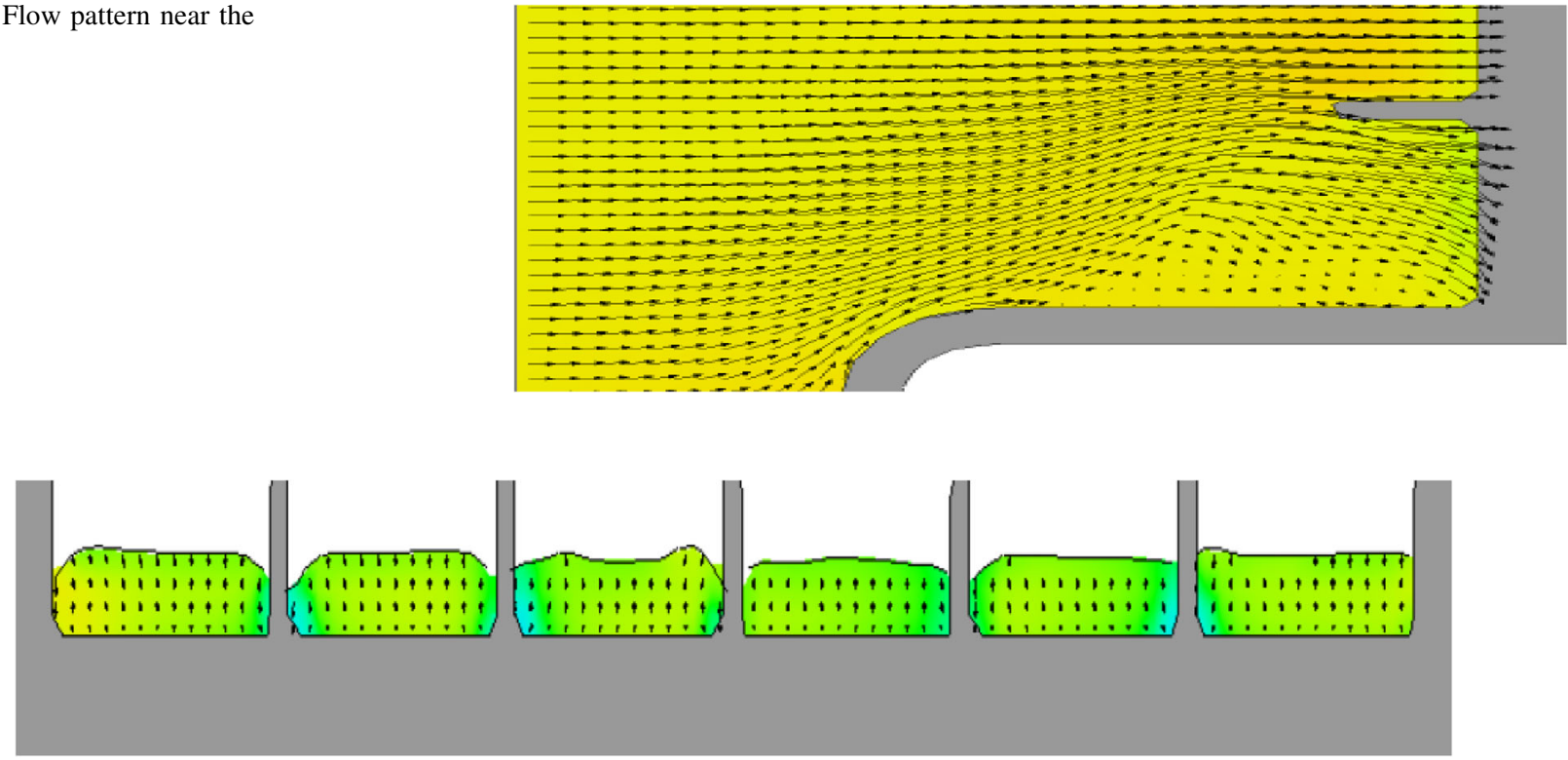

Fig. 13 Two-dimensional flow pattern on the wall of the spillway crest guidance

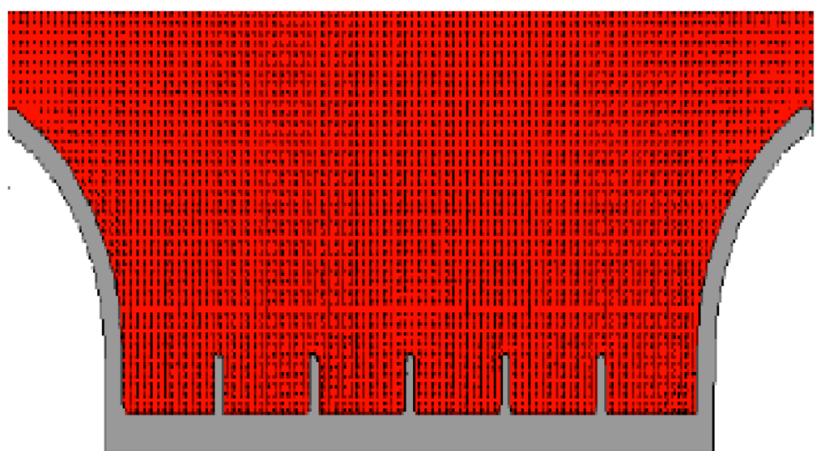

Fig. 14 Proposed a model for the flow rate of $120(\mathrm{~L} / \mathrm{s})$

smallest. With fining the size of mesh the accuracy of model is increased; whereas, the cost of computation is increased. In this research, the value of upstream boundary condition was adjusted with measured data during the experimental studies on the scaled model and the mesh size was equal to $1 \times 1 \times 1 \mathrm{~cm}^{3}$.

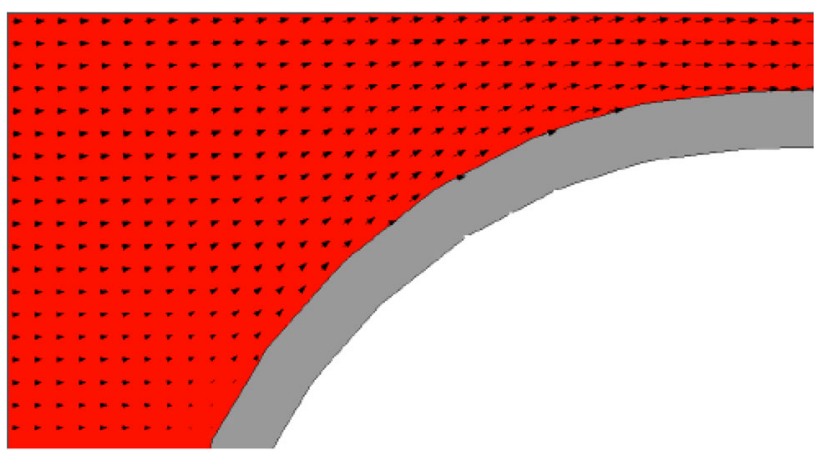

Fig. 15 To guide the flow pattern near the wall

\section{Results and discussion}

The behavior of water in spillway is strongly affected by the flow pattern at the entrance of the spillway, the flow pattern formation at the entrance is affected by the guide wall, and choice of an optimized form for the guide wall 
Fig. 16 Two-dimensional flow pattern on the wall of the spillway crest

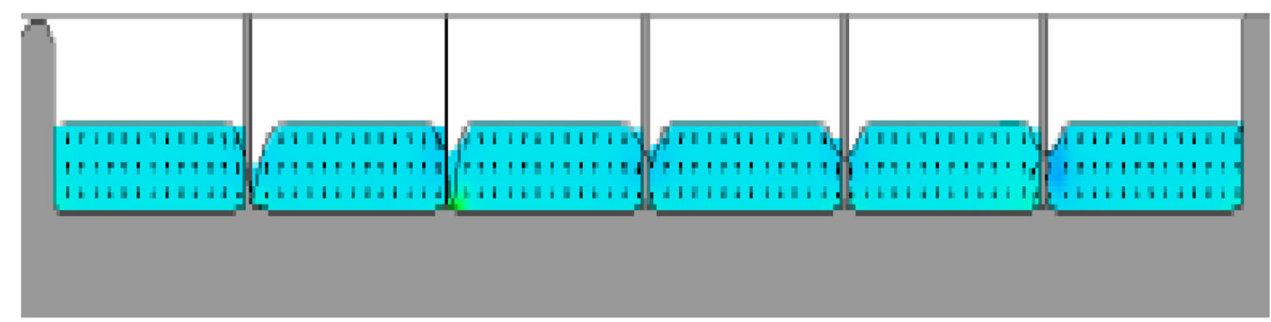

has a great effect on rising the ability of spillway for easy passing the PMF, so any nonuniformity in flow in the approach channel can cause reduction of spillway capacity, reduction in discharge coefficient of spillway, and even probability of cavitation. Optimizing the flow guiding walls (in terms of length, angle and radius) can cause the loss of turbulence and flow disturbances on spillway. For this purpose, initially geometry proposed for model for the discharge of spillway dam, Kamal-Saleh, 80, 100, and $120(\mathrm{~L} / \mathrm{s})$ were surveyed. These discharges of flow were considered with regard to the flood return period, 5, 100 and 1000 years. Geometric properties of the conducting guidance wall are given in Table 1 .

Results of the CFD simulation for passing the flow rate $80(\mathrm{~L} / \mathrm{s})$ are shown in Fig. 3. Figure 3 shows the secondary flow and vortex at the left guide wall.

For giving more information about flow pattern at the left and right guide wall, Fig. 4 shows the flow pattern at the right side guide wall and Fig. 5 shows the flow pattern at the left side guide wall.

With regard to Figs. 4 and 5 and observing the streamlines, at discharge equal to $80(\mathrm{~L} / \mathrm{s})$, the right wall has suitable performance but the left wall has no suitable performance and the left wall of the geometric design creates a secondary and circular flow, and vortex motion in the beginning of the entrance of spillway that creates cross waves at the beginning of spillway. By increasing the flow rate $(Q=100 \mathrm{~L} / \mathrm{s})$, at the inlet spillway secondary flows and vortex were removed, but the streamline is severely distorted. Results of the guide wall performances at the $Q=100(\mathrm{~L} / \mathrm{s})$ are shown in Fig. 6.

Also more information about the performance of each guide wall can be derived from Figs. 7 and 8. These figures uphold that the secondary and vortex flows were removed, but the streamlines were fully diverted specifically near the left side guide wall.

As mentioned in the past, these secondary and vortex flows and diversion in streamline cause nonuniformity and create cross wave through the spillway. Figure 9 shows the cross waves at the crest of the spillway.

The performance of guide walls at the $\mathrm{Q}=120(\mathrm{~L} / \mathrm{s})$ also was assessed. The result of simulation is shown in Fig. 10. Figures 11 and 12 show a more clear view of the streamlines near to right and left side guide wall, respectively. As seen in Fig. 12, the left side wall still causes vortex flow and creation of and diversion in streamline.

The results of the affected left side guide wall shape on the cross wave creation are shown in Fig. 13. As seen from Fig. 3, the left side guide wall also causes cross wave at the spillway crest.

As can be seen clearly in Figs. 9 and 13, by moving from the left side to the right side of the spillway, the cross waves and the nonuniformity in flow is removed. By reviewing Figs. 9 and 13, it is found that the right side guide wall removes the cross waves and nonuniformity. With this point as aim, a geometry similar to the right side guide wall was considered instead of the left side guide wall. The result of simulation for $Q=120(\mathrm{~L} / \mathrm{s})$ is shown in Fig. 14. As seen from this figure, the proposed geometry for the left side wall has suitable performance smoothly passing the flow through the approach channel and spillway.

More information about the proposed shape for the left guide wall is shown in Fig. 15. As seen from this figure, this shape has suitable performance for removing the cross waves and vortex flows.

Figure 16 shows the cross section of flow at the crest of spillway. As seen in this figure, the proposed shape for the left side guide wall is suitable for removing the cross waves and secondary flows.

\section{Conclusion}

Analysis of behavior and hydraulic properties of flow over the spillway dam is a complicated task which is cost and time intensive. Several techniques suitable to the purposes of study have been undertaken in this research. Physical modeling, usage of expert experience, usage of mathematical models on simulation flow in one-dimensional, two-dimensional and three-dimensional techniques, are some of the techniques utilized to study this phenomenon. The results of the modeling show that the CFD technique is a suitable tool for simulating the flow pattern in the guide wall. Using this tools helps the designer for developing the optimal shape for hydraulic structure which the flow pattern through them are important. 


\section{References}

Chanson H (2004) 19-Design of weirs and spillways. In: Chanson H (ed) Hydraulics of open channel flow, 2nd edn. ButterworthHeinemann, Oxford, pp 391-430

Chatila J, Tabbara M (2004) Computational modeling of flow over an ogee spillway. Comput Struct 82:1805-1812

Das MM, Saikia MD (2009) Irrigation and water power engineering. PHI Learning, New Delhi

E, Department Of Army: U.S. Army Corps (2013) Hydraulic Design of Spillways. BiblioBazaar, Charleston

Fattor C, Bacchiega J (2009) Design conditions for morning-glory spillways: application to potrerillos dam spillway. Adv Water Res Hydraul Eng Springer, Berlin, pp 2123-2128

Gessler D (2005) CFD modeling of spillway performance. Impacts Glob Clim Change. doi:10.1061/40792(173)398

Kim D-G (2007) Numerical analysis of free flow past a sluice gate. KSCE J Civ Eng 11:127-132

Kim D, Park J (2005) Analysis of flow structure over ogee-spillway in consideration of scale and roughness effects by using CFD model. KSCE J Civ Eng 9:161-169

Kim S, Yu K, Yoon B, Lim Y (2012) A numerical study on hydraulic characteristics in the ice Harbor-type fishway. KSCE J Civ Eng $16: 265-272$

Ma X-D, Dai G-Q, Yang Q, Li G-J, Zhao L (2010) Analysis of influence factors of cavity length in the spillway tunnel downstream of middle gate chamber outlet with sudden lateral enlargement and vertical drop aerator. J Hydrodyn Ser B 22:680-686

Milési G, Causse S (2014) 3D numerical modeling of a side-channel spillway. In: Gourbesville P, Cunge J, Caignaert G (eds) Advances in hydroinformatics. Springer, Singapore, pp 487-498
Montagna F, Bellotti G, Di Risio M (2011) 3D numerical modeling of landslide-generated tsunamis around a conical island. Nat Hazards 58:591-608

Novak P, Moffat AIB, Nalluri C, Narayanan R (2007) Hydraulic structures. Taylor \& Francis, London

Parsaie A, Haghiabi A (2015a) Computational modeling of pollution transmission in rivers. Appl Water Sci. doi:10.1007/s13201-0150319-6

Parsaie A, Haghiabi A (2015b) The effect of predicting discharge coefficient by neural network on increasing the numerical modeling accuracy of flow over side weir. Water Res Manag 29:973-985

Parsaie A, Yonesi H, Najafian S (2015) Predictive modeling of discharge in compound open channel by support vector machine technique. Model Earth Syst Environ 1:1-6

Su P-L, Liao H-S, Qiu Y, Li CJ (2009) Experimental study on a new type of aerator in spillway with low Froude number and mild slope flow. J Hydrodyn Ser B 21:415-422

Suprapto M (2013) Increase spillway capacity using Labyrinth Weir. Procedia Eng 54:440-446

Tabbara M, Chatila J, Awwad R (2005) Computational simulation of flow over stepped spillways. Comput Struct 83:2215-2224

Wang J, Chen H (2009) Experimental study of elimination of vortices along guide wall of bank spillway. Adv Water Res Hydraul Eng Springer, Berlin, pp 2059-2063

Wang Y, Jiang C (2010) Investigation of the surface vortex in a spillway tunnel intake. Tsinghua Sci Technol 15:561-565

Zhenwei MU, Zhiyan Z, Tao Z (2012) Numerical simulation of 3-D flow field of spillway based on VOF method. Procedia Eng $28: 808-812$ 